\title{
High diversity of Cushing's disease in patients with corticotroph macroadenoma
}

\author{
Maria Kurowska, Joanna Malicka, Jerzy S. Tarach \\ Department of Endocrinology, Medical University, Lublin, Poland
}

Introduction. Cushing's disease is usually caused by corticotroph microadenoma, but in $7 \%-20 \%$ of cases it is due to ACTHproducing macroadenoma. There are a lot differences in clinical and biochemical characteristic of Cushing's disease depending on size of pituitary adenoma. There is an evidence that macroadenomas causing Cushing's disease are more refractory to surgical treatment and show variable response to adjunctive radiotherapy or farmacological therapy.

Material and methods. Retrospective analysis of medical records of 9 patients [5F; 4M] hospitalized in 2002-2015.

Results. Four of the patients [ $2 \mathrm{~F}$ and $2 \mathrm{M}$ ] were diagnosed before they were 40 years old [mean age 28.5] and 5 [3 $\mathrm{F}$ and $2 \mathrm{M}$ ] over 40 years old [mean age 50 ].

In 3 women tumour was initially discovered as microadenoma. A woman [23 years old] first underwent bilateral adrenalectomy because of inability to neurosurgery and 5 years later Nelson's syndrome developed. In two consecutive cases [49y and 52y] at the moment of diagnosis MRI revealed microadenomas $9 \times 7 \mathrm{~mm}$ and $5 \times 4 \mathrm{~mm}$ respectively. In the first female 2 years after initial neurosurgery consecutive 4 transsphenoidal reoperations, stereotactic radiotherapy and bilateral adrenalectomy were conducted. Then she developed Nelson's syndrome. Propter a rapid tumour's invasion, themozolomide and bevacuzimab were introduced. She died 7 years after the diagnosis. In the second patient tumour regrowth was observed 6 years after the first neurosurgery and because of failure of second adenomectomy and mild hypercortisolism she was qualified to pasireotyd therapy.

In 6 patients [ $2 \mathrm{~F}$ and $4 \mathrm{M}$ ] the pituitary tumours were initially diagnosed as macroadenomas. One patient with $5 \mathrm{~cm}$ tumour size and overt hypercortisolism died after first craniotomy. Another patient presented cyclic Cushing's syndrome with pituitary macroadenoma discovered after 7 years observation.

In the next patient unique cause of Cushing's disease was Crooke's macroadenoma, refractory to two neurosurgeries with good response to themozolomide.

In $\mathbf{2}$ cases [female and male] macrocorticotropinomas were discovered as incydentalomas and operated as clinically inactive (silent) tumours. In these patients the tumour recurred 5 years after the first neurosurgery and visible hypercortisolism developed.

Tab.1 Patients with Cushing's disease caused primarily by corticotroph microadenoma

\begin{tabular}{|c|c|c|c|c|c|c|}
\hline Patient & Gender & Age & $\begin{array}{l}\text { Micro } \\
\text { size } \\
\mathrm{mm}\end{array}$ & $\begin{array}{l}\text { Macro } \\
\text { Size } \\
\mathrm{mm}\end{array}$ & $\begin{array}{c}\text { ACTH } \\
\text { in micro } \\
\text { stadium }\end{array}$ & $\begin{array}{c}\text { ACTH } \\
\text { in macro } \\
\text { stadium }\end{array}$ \\
\hline FU & $\mathbf{F}$ & 23 & $<5$ & $17 \times 35$ & - & $\begin{array}{c}10560 \mathrm{pg} / \mathrm{ml} \\
{[\mathrm{n}: 10-46]}\end{array}$ \\
\hline MB & $\mathbf{F}$ & 49 & $9 \times 7$ & $34.4 \times 39.2$ & $\begin{array}{c}81 \mathrm{pg} / \mathrm{ml} \\
{[\mathrm{n}:<46]}\end{array}$ & $\begin{array}{c}23830 \mathrm{pg} / \mathrm{ml} \\
\text { [n:7.2-63.3] }\end{array}$ \\
\hline SM & $\mathbf{F}$ & 52 & $5 \times 4$ & $15 \times 15 \times 10$ & - & $\begin{array}{c}93 \mathrm{pg} / \mathrm{ml} \\
{[\mathrm{n}: 7.2-63.3]}\end{array}$ \\
\hline
\end{tabular}

The aim of the study was to present our observations concerning etiologic, clinical and therapeutic diversity of Cushing's disease in patients with macrocorticotropinomas.

Conclusion. Macrocorticotropinomas are very heterogenic group of pituitary tumours with high etiologic, clinical and therapeutic diversity.

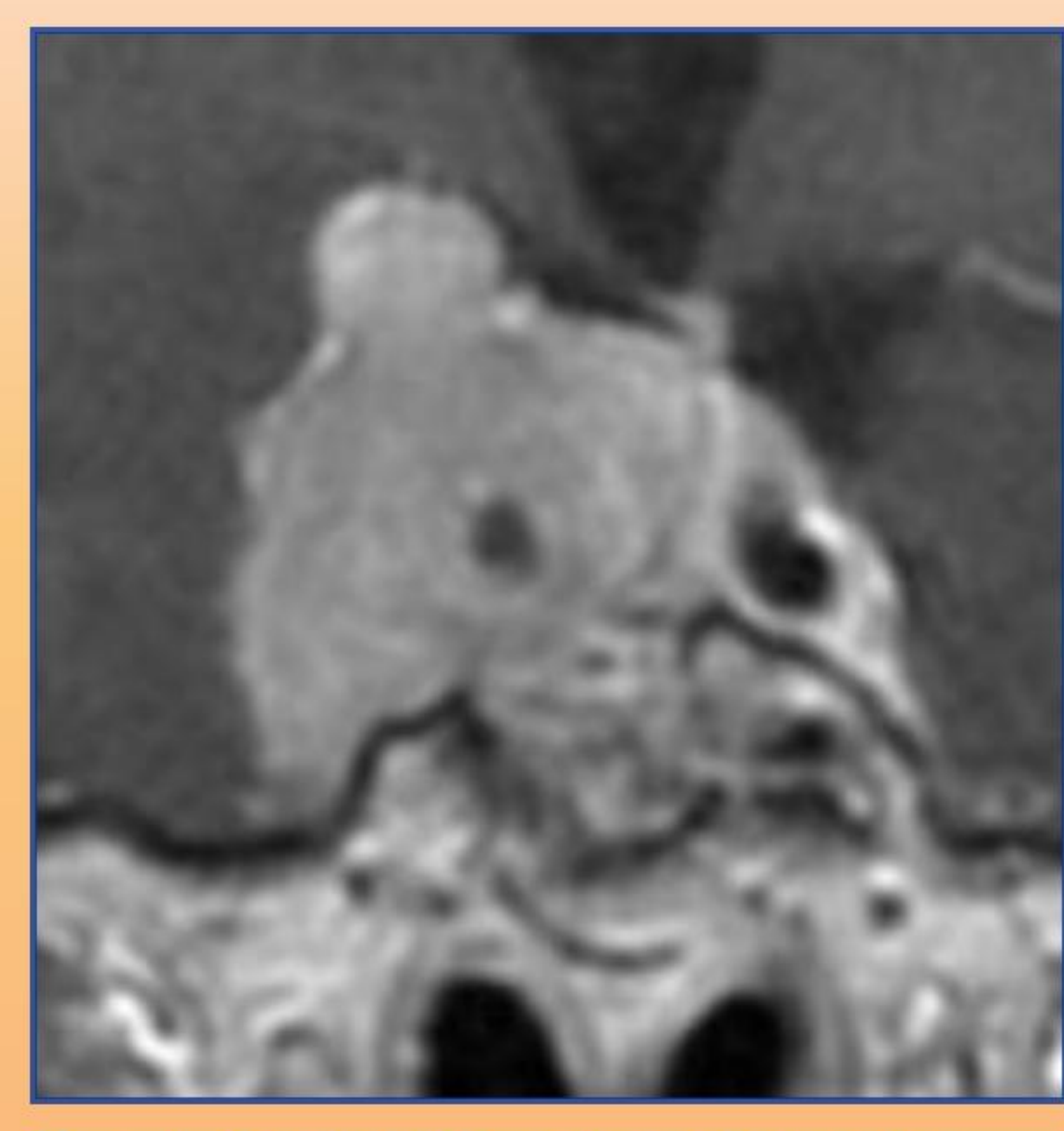

Ryc. 1 Frontal MR picture of invasive corticotroph macroadenoma in patient with primarily diagnosed microadenoma.

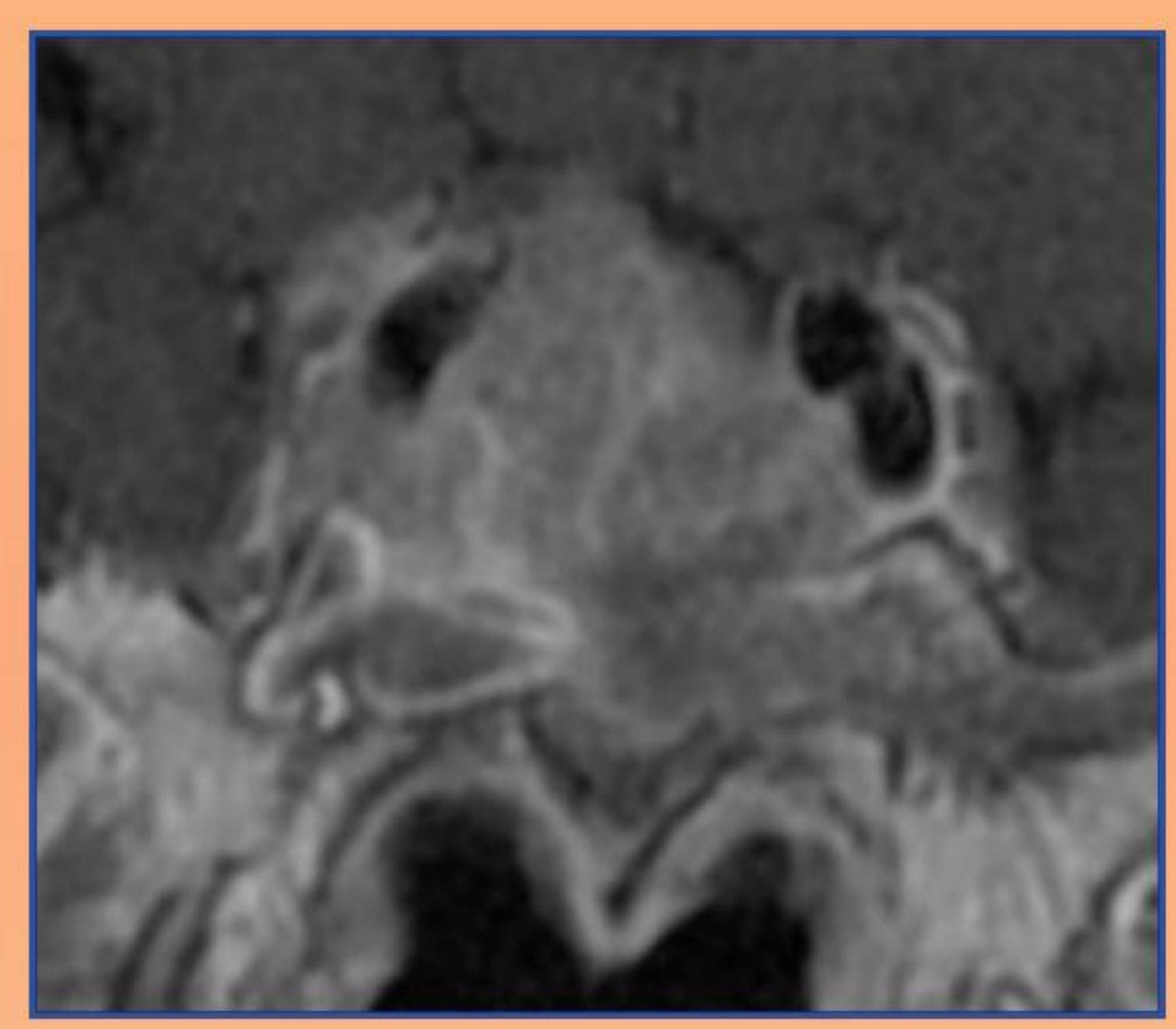

Ryc.3 Frontal MR picture in patient with Crooke's cell macroadenoma

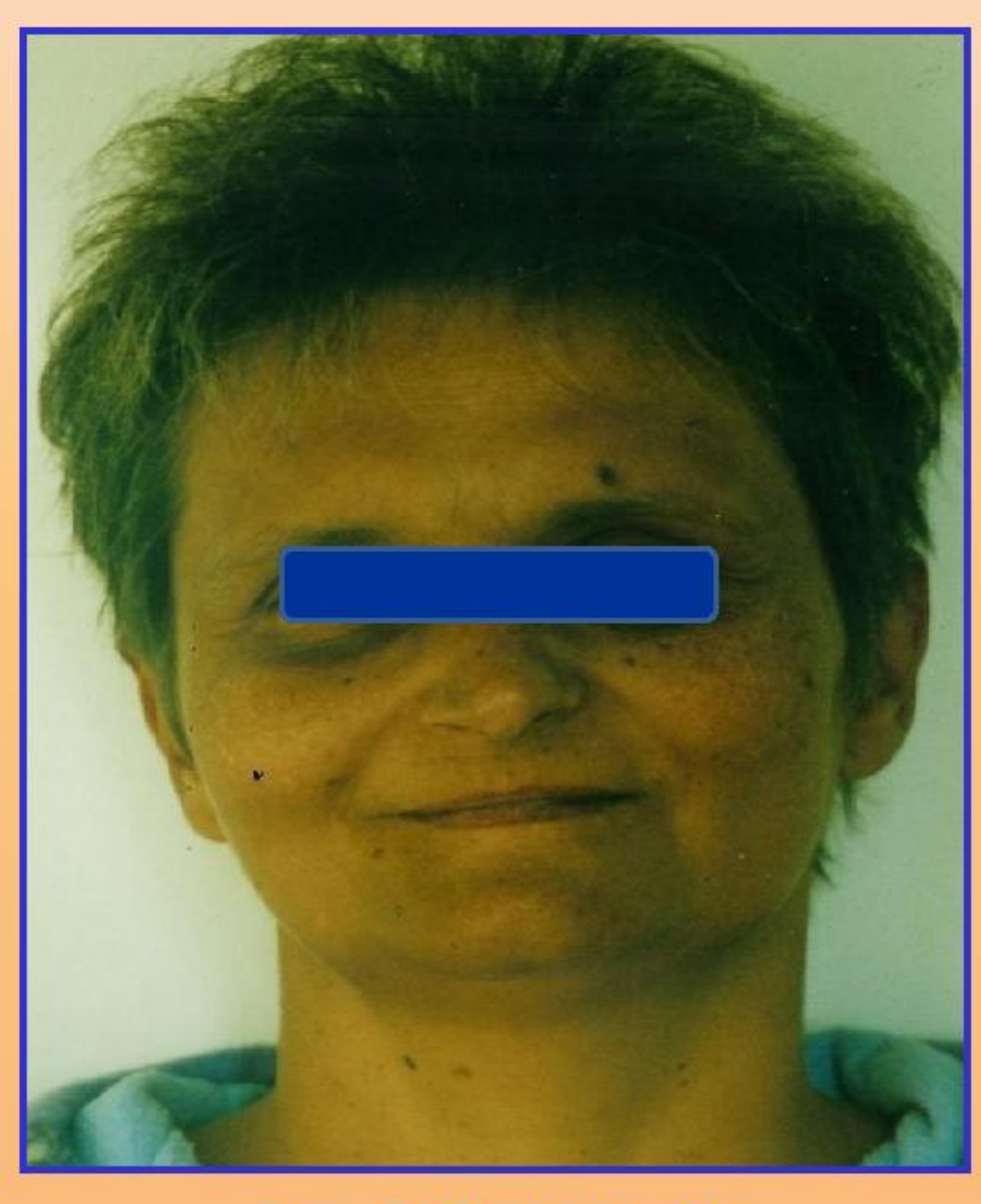

Ryc. 2 Patient with macroadenoma in Nelson's syndrome

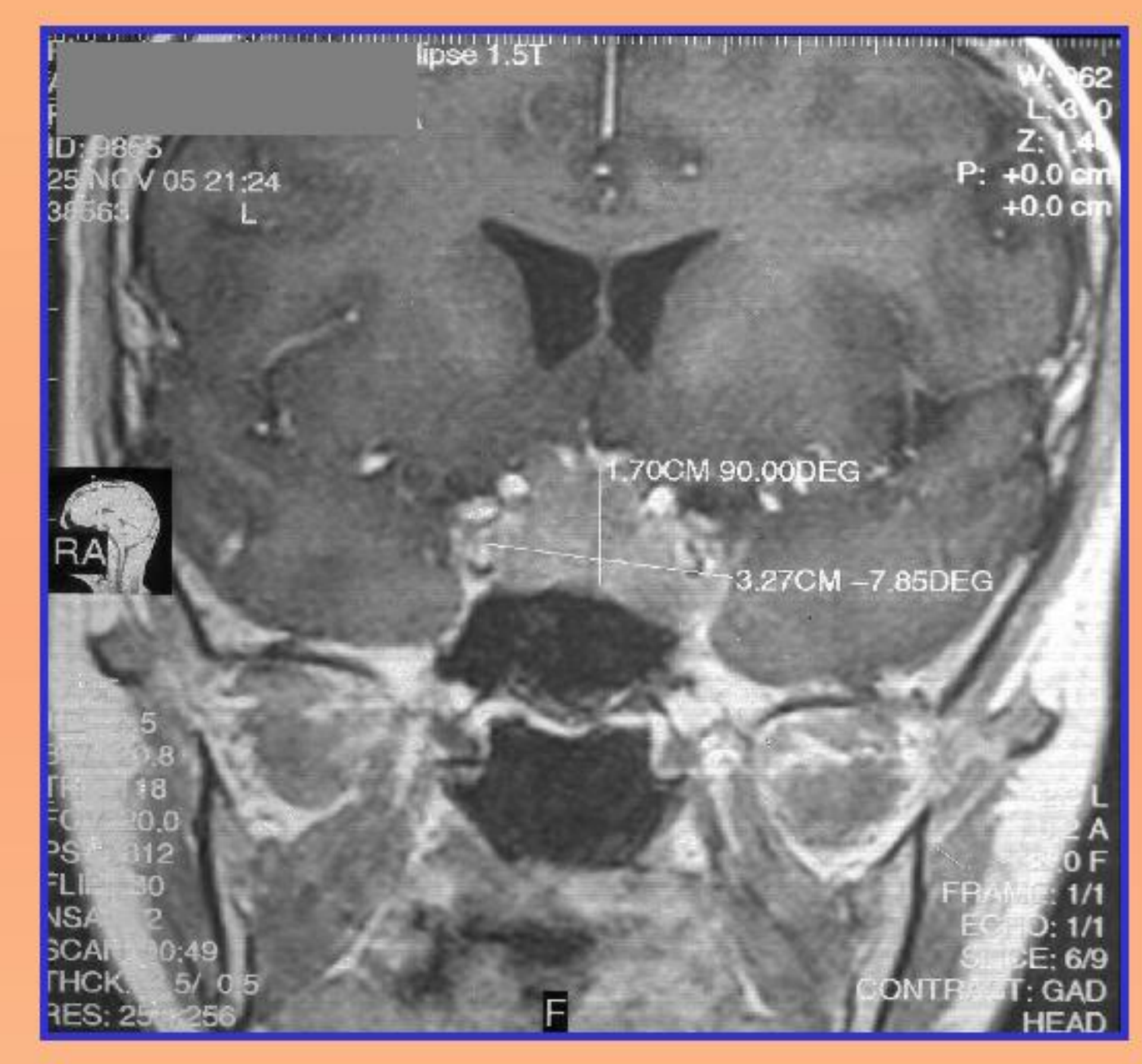

Ryc. 4 Frontal MR in patient with Nelson syndrome
Tab.2 . Patients with Cushing's disease caused primarily by macrocorticotrophinoma

\begin{tabular}{|c|c|c|c|c|}
\hline Patient & Gender & Age & $\begin{array}{l}\text { Macrotumour } \\
\text { size } \mathrm{mm}\end{array}$ & ACTH level pg/ml \\
\hline FE & M & 28 & $60 \times 40 \times 40$ & 219 [n: 10-46] \\
\hline LW & $M$ & 51 & $32 \times 29 \times 24$ & 170 [n:7.2-63.6] \\
\hline $\mathrm{CZ}$ & $M$ & 37 & $50 \times 30 \times 40$ & $68.2[n: 10-46]$ \\
\hline GW & $\mathbf{M}$ & 56 & $15 \times 13 \times 15$ & 217.5 [n:7.2-63.6] \\
\hline SE & $\mathbf{F}$ & 31 & $22 \times 18 \times 12$ & 68.2 [n:10-46] \\
\hline OK & $\mathbf{F}$ & 66 & $23 \times 17 \times 15$ & 17.63 [n:7.2-63.6] \\
\hline
\end{tabular}

